\title{
Financial Evaluation of Drug Addiction Rehabilitation Services with Respect to the Health Economics
}

\author{
Asst. Prof. Dr. Osman Altay (Beykent University, Turkey) \\ Ph.D. Candidate Hatice Mutlu (Üsküdar University, Turkey)
}

\begin{abstract}
Healthcare interventions are concern of government policies, health service providers, civil society organizations and public. These interventions are mainly criticized with respect to their cost effectiveness. However, economic, social and health benefits of drug addiction rehabilitation services are not well understood and they remain relatively subsidized in comparison to other aspects of healthcare interventions. But, notwithstanding this, drug addiction rehabilitation services are generally financed with public funds in Turkey as like many other countries and this situation become subject to questioning when fiscal policies and cost effectiveness of these services are considered.

Based on this circumstances there is a great need for scientifically sound and practical financial and economic evaluation of substance abuse treatment services. In Turkey, recent legislative developments on substance abuse treatment services provide a baseline for structural evaluation of financial and economic feasibility of these services. In spite of ongoing methodological and empirical developments in economic evaluation of the primary health services, similar studies regarding addiction treatments are very rare in the literature. Correspondingly, methodological guidelines in this area are also very limited.

This study addresses these gaps by presenting a financial and economic evaluation of drug addiction rehabilitation services in Turkey considering urgent need of intervention in this area. Evaluation of these services is based on the basic requirements of a drug addiction rehabilitation center, which is determined by the related legislation in Turkey, and the evaluation was conducted according to the methodological principles presented by EMCDDA, European Monitoring Centre for Drugs and Drug Addictions.
\end{abstract}

\section{Introduction}

Having gradually increased in recent years, drug misuse and drug/substance addiction have become one of the most serious social problems. In addition to its effects on individuals, drug addiction exerts impacts on every segment of society and poses a problem at the international level. Moreover, it affects not only users but also their families and social circles, consequently the whole society. Therefore, the fight against addiction needs to be carried out systematically and at societal rather than individual level.

The United Nations Office on Drug and Crime (UNODC) delivers a World Drug Report biyearly, and one report states that 271 million people around the world used drugs in 2017, which accounts for $5.5 \%$ of the world population aged 15-64. The rate is 3.1 for Turkey (TUBIM 2018). The 2017 report sets forth also that, among the users, 35 million people suffer from drug use disorders; of them, only one in seven gets treatment and in 2017, the global drug-related death toll was 585 thousand (UNODC, 2019).

Turkey experienced a two-fold increase in drug use from 2002 to 2011. Accordingly, drug-related deaths doubled through 2009-2013, and drug law offenses escalated by 50\% through 2011-2013 (TUBİM, 2014). That brought with its healthcare costs, drug-related crimes, and deaths.

Compiled by the EMCDDA, the 2019 European Drug Report exhibits that the amount of heroin seized in Turkey in one year is surpassingly higher than that seized in all the European countries. It is also reported that drug law offenses in Turkey rose by $45 \%$ in 2017 , and most of the offenses were caused by drug use and possession. According to the data in the report, there occurred an upward trend in the number and rate of drug overdose deaths in Turkey. 105 people died of drug use in 2011. The number increased to 920 in 2016 and reached 941 in 2017. Besides, most of the decedents were male and the average age was 32 (EMCDDA, 2019).

In Turkey, drug users getting treatment are mostly male. The Republic of Turkey Ministry of Health offers detoxification services to drug addicts at Alcohol and Drug Treatment Centers (These centers are called as AMATEM in Turkish as an abbreviation). Detoxification-oriented inpatient treatment options grow in parallel with the increased number of AMATEMs.

Figures regarding treatment services at the substance addiction facilities between 2014-2016 are indicated at the following table. 


\begin{tabular}{|r|r|r|r|}
\hline YEAR & OUTPATIENCE & INPATIENCE & TOTAL \\
\hline 2014 & 237.335 & 10.167 & 247.502 \\
\hline 2015 & 181.622 & 12.327 & 193.949 \\
\hline 2016 & 226.118 & 13.006 & 239.124 \\
\hline
\end{tabular}

Table 1: Number of Substance Addiction Outpatient \& Inpatient Treatment in Turkey between 2014- 2016 (Ulu 2018)

Looking at their profile, the drug addict population in our country is young, has a high unemployment rate and low education level, and lives with their family. $47 \%$ of those seeking treatment are aged 15-24, and age at first use is 20 on average. $66 \%$ of the treatment-seekers are unemployed and earn less than 500 TL monthly. $70 \%$ of the addicted individuals have a high school or lower degree; \%96 live with their families, and 38\% started doing drugs because of their families and social circles (TUBIM, 2014).

The magnitude of the risk and harms it produces establish the significance of the fight against drugs. It is a fact that detoxification forms an indispensable part both in the fight against drugs and the treatment of addicts. On the other hand, the need for capacity increase in detoxification services as well as for developing rehabilitation services for relapse prevention is a generally accepted issue.

In its fight against non-communicable diseases, the World Health Organization emphasizes that the world faces new challenges in view of the health and demographic trends, and the number of individuals with noncommunicable diseases is on the rise the same way as the outcomes they produce (WHO, 2018). Accordingly, it becomes more vital to invest in rehabilitation as it does not only decrease mortality and morbidity but also improves functionality, thus welfare. Economic and social consequences of meeting that investment need will contribute to social welfare, too.

It is accepted that illicit drug use worsens the global disease burden (Rehm J, et al, 2017; Degenhardt L, Hall W., 2012) Chronicle problems include communicable diseases induced by addiction and drugs whereas there are well-documented acute harms such as overdose.

Understanding the costs of drug-related actions stands as an essential dimension of policy-making and evaluation. On the other hand, we have poor and heterogeneous information on drug-related public expenditures in Europe, at both the local and national levels. According to estimates submitted to EMCDDA in the last decade, expenditures made on demand reduction efforts using the total medication budget represent $21 \%$ to $75 \%$ of the drug-related public expenditures and vary considerably among countries. It is estimated that, in the European Union, 1.1103 million people (1.5 million when Norway and Turkey included) got treatment for illicit drug use. Individual application is seen as the ideal and widespread way of starting the drug treatment process. In Europe, most of those in replacement therapy are over 35 years of age and have been under treatment for more than 2 years. The replacement therapy, usually combined with psychosocial interventions, is the most common treatment for opioid addiction. The evidence available supports this combined approach, which produces positive outcomes in terms of retention, illicit opioid use rate, reported risk behaviors, as well as drug-related harms and death rates (EMCDDA, 2019).

Drug treatment and other relevant healthcare costs make up the biggest part of the estimated expenditures on demand reduction initiatives. National differences come into view partly because of diverse policies and service options. In addition, various estimation methodologies used, along with the diversity of the drug problems and of public service provision, produce a serious impact on the outcomes.

Reducing overdose-induced disease and death rates forms a serious public health challenge in Europe. Extensive public health reflex in this field aims to reduce vulnerability among drug users by removing obstacles, making the services accessible and encouraging users to take fewer risks.

The scope of treatment for drug-related problems was extended in mid-90s, which is one of the reasons why the number increased. Again, there arose an intensified pressure on service providers to offer more effective services

The literature is poor when it comes to drug treatment expenditures. In the past 10 years, 18 European countries reported comprehensive estimates of expenditures by central governments including drug treatment costs. The said reports show that total drug-related public expenditures account for $0.01-0.5 \%$ of GDP. The share of health expenditures in total drug-related public expenditures varies from $\% 15$ to 53\% (EMCDDA, 2017).

\section{Setting a Methodology for Cost-Effectiveness Analysis}

Since drug addiction is a public health issue with social and economic aspects, making cost-effective policies and taking cost-effective actions grow in importance in consideration of the needs and circumstances relating to drug addiction rehabilitation services. The European Union Drugs Strategy 2013-2020 and Action Plan 2017-2020 were prepared by taking this fact into account. In line with the requirements set forth in those strategies, EMCDDA makes efforts to develop analytic tools for evaluating the effectiveness of drug policies and actions, and thereby to contribute to the estimation of expenditures borne by EU countries when fighting against drug addiction. The 
insufficient data on the issue along with the uncertainty in the transfer of funds for drug treatment pose an obstacle to the effective allocation of sources.

It is not easy to analyze public expenditures on drug treatment because the data on related expenditures is not satisfactory for EU countries and Turkey. Therefore, by using conventional cost analysis methods, this study seeks to determine the cost of rehabilitation work to be carried out at a rehabilitation center that will be founded in compliance with standards established by the Regulation on Addiction Counseling, Detoxification and Rehabilitation Centers. It does also take into account the scope of approach in the "Drug Treatment Expenditure: a methodological overview" in which the EMCDDA compiled drug rehabilitation efforts from different countries and evaluated methodologies used in them with a unique approach. For the purposes of this study, the possible fiscal burden on public finance is estimated by subjecting the defined unit costs to a projection using the available data and countries' data in the EMCDDA publications. The said financial burden was evaluated together with the external benefits of the rehabilitation services. Rehabilitation services create benefits for addicted individuals; expenditures induced by individuals' dependence go down and social welfare improves with their participation in the labor force. Therefore, such benefits should also be taken into account in the evaluation.

It should be emphasized that medical treatment services and rehabilitation services are two different processes in the treatment of drug addicts. The medical treatment refers rather to detoxification of a given addict within the rehabilitation process. Following the medical treatment, individuals need to be cleaned from psychological, social and environmental impacts of addiction. Otherwise, the relapse risk increases for addicts who have not been empowered against such impacts, which stands as a cost-increasing element (EMCDDA, 2017). Individuals who return to the same social environment without getting any support after medical treatment go back to the addiction cycle inevitably. The current situation lower treatment success rates whereas the addicts resuming the medical treatment over and over put great pressure on AMATEMs (Alkol ve Madde Tedavi Merkezi - Alcohol and substance addiction treatment center) and CEMATEMs (Çocuk ve Ergen Madde Bağımlılı̆̆ Tedavi Merkezleri Substance addiction treatment center for children and adults). Treatment success rates are likely to go up substantially with the foundation of rehabilitation centers.

Addicts' taking up drugs after medical treatment, recurrence, in other words, is named "relapse" in the literature. The relapse rate is $60 \%$ in our country against $30 \%$ in developed countries. This study analyses the costeffectiveness to be created if the relapse rate would be reduced to $45 \%$ through rehabilitation services to be offered after detoxification.

Although not included in this study's scope, expenditures to be borne for the inclusion of addicts into rehabilitation process may achieve savings on the following cost items in terms of public finance:

- Treatment of other health problems caused by drug use (Communicable diseases; HIV, Hepatitis, etc., problems with kidneys, lungs or other visceral organs, and mental problems, etc.)

- Costs relating to law enforcement and legal procedures.

Some literature works assert that each penny spent within an integrated ecosystem uniting medical treatment, rehabilitation and social cohesion returns the system 15-20 times more benefits. In reference to the data published by Public Health England, every pound invested in drug treatment has a social return of 21 pounds over a 10-year period whereas the ratio is 1:26 for alcohol treatment (Public Health England 2012).

Health economists have employed various economic evaluation methods and techniques to evaluate healthcare service programs, services or interventions. The primarily used one is the economic cost analysis. Economic cost analysis tries to estimate the opportunity cost of a program from a societal point of view. The opportunity cost grounds itself on market prices of all the sources used for the provision of a given program (French, M. T., Salomé, H. J., Sindelar, J. L., \& McLellan, A. T., 2002).

In that regard, the ruling economic evaluation method is the benefit-cost analysis (Cartwright, 1998; French, 2002; Alexandre et al., 2012; French et al., 2000). This technique creates a monetary measurement comparing a program's opportunity cost to its economic benefit. The results are called benefit-cost ratio or net benefit (benefitcost) estimate. If the benefit-cost ratio is above 1 or net benefit estimate is positive, the intervention in question is cost wise beneficial. This study adopted that approach in running the analysis.

Today, 40 alcohol and drug addiction centers operate in Turkey under the Ministry of Health (AMATEM ÇEMATEM) These centers provide both inpatient and outpatient treatment, and minor and adult inpatients are treated in separate centers. Very often news about the insufficient capacity of AMATEMs and CEMATEMs come to public agenda (Drug Related News n.d.) High relapse rates are considered one of the reasons why those centers fail to meet the demand that exceeds their capacities. Forming a basis for this study, the Regulation on Addiction Counseling, Detoxification, and Rehabilitation Centers, issued on March 10, 2019, aims to carry into effect arrangements for establishing and operating centers where drug addicts will get inpatient and outpatient pharmacological treatment in addition to psycho-social therapy and rehabilitation (T.C. Resmi Gazete 2019). Therefore, present 40 centers, which provide detox-oriented pharmacological therapy, need to be turned into ones that rehabilitate addicted individuals with pscyhosocial support, with a view to reintroducing them to the social 
life. In that regard and in the first stage, it is planned and advised by experts that each AMATEM and CEMATEM work in close cooperation with a rehabilitation center. For this reason, this study will make analysis over the costs to be induced with the establishment of 40 rehab centers across Turkey.

Before making the cost analysis, this study examined the cost analyses that works of national and international literature made on healthcare services and methodologies. Then, it analyzed the cost of rehabilitation services to be provided for drug addiction (alcohol and substance) in Turkey within the scope of the regulation that sets out the rules for the field.

Healthcare costs can be classified into the following main categories (axes); however, it has been established that developing a methodology based on a single axis will not be possible because each will have a scope and functionality with differing extents.

Axes:

1 - Healthcare Functions

2 - Healthcare Providers

3 - Funding Schemes

Drug treatment expenditures can be estimated, sorted and categorized by healthcare service functions (axis 1), healthcare service providers (axis 2) or healthcare service financing plans (axis 3). Classifying healthcare expenditures according to healthcare service functions may follow treatment provision modalities such as withdrawal, rehabilitation, and pharmacotherapy, etc. Thereby, expenditures in each category can be calculated. As an alternative, healthcare expenditures can be calculated according to providers, which can be hospitals, inpatient and outpatient service providers, etc. Categorization by practitioner type is helpful for thinking through the types of expenditure data because in many instances the type of expenditure data is linked to the type of practitioner (EMCDDA, 2017).

The regulation already sets forth what qualifications' practitioners must have at which providers, as well as cost items and categories for Turkey. Therefore, this study has made a cost analysis on rehabilitation-oriented services bearing in mind the minimum conditions established by the regulation.

\section{Evaluating the Cost of Rehabilitation Services in Turkey within the Limits of Legislative Regulations}

There are three main international conventions on drug policies: the Single Convention on Narcotic Drugs of 1961, 1971 Convention on Psychotropic Substances, and the United Nations Convention Against Illicit Traffic in Narcotic Drugs and Psychotropic Substances of 1988. Those conventions have contexts guiding and regulating states' policies in fighting the supply of addictive substances. The conventions were concluded with the goal of a drug-free world and they set an overall framework for nation-states' drug policies.

The spread of drug use across the world in recent years provoked discussions on the efficiency of present conventions and the policies derived from them. It came to be debated that current conventions and national policies needed to be revised with a wide range of strategic practices and approaches. Prominent approach generating from such discussion argues that it will be more efficient if drug policies are shaped with a local-tointernational approach rather than international-to-local. So, encouragement is offered to studies and models that will mobilize the current dynamics with this approach.

In addition to the national anti-drug policies and common legal regulations, the Regulation on Addiction Counseling, Detoxification, and Rehabilitation Centers, promulgated on March 10, 2019, is the most significant legal foundation regulating the rehabilitation services in Turkey. It was put into effect for the purposes of eliminating uncertainties in the field and delivering evidence-based services to the target group.

When making a rehabilitation cost evaluation one may benefit from inputs such as the minimum conditions to be fulfilled by a center that will be founded to provide rehabilitation services in compliance with the arrangements established by the regulation in terms of set-up, operation and treatment processes. The cost elements in the regulation were checked to determine the cost elements to be covered in this evaluation. So, the cost items may be divided as set-up and operating costs, as is the case in other investments. The set-up and operating cost items of a rehabilitation center for 20 patients, meeting the minimum criteria in the regulation, may be identified under the following categories: 


\begin{tabular}{|c|c|}
\hline Setup Cost Items: & Operating Cost Items: \\
\hline - Land Cost & - $\quad$ Salaries (Gross Wages) \\
\hline - $\quad$ Construction Cost & - Operating expenses: \\
\hline $\begin{array}{l}\text { - Equipment and Furnishing } \\
\text { (IT Infrastructure, Furniture, Whiteware, } \\
\text { Fittings, etc. included) }\end{array}$ & $\begin{array}{ll}\circ & \text { Electricity, Water, Gas } \\
\circ & \text { Transportation } \\
\circ & \text { Kitchen/Food }\end{array}$ \\
\hline - $\quad$ Staff Training & $\begin{array}{ll}\circ & \text { Cleaning } \\
\circ & \text { Stationery } \\
\circ & \text { Maintenance \& Repair, Amortization } \\
\circ & \text { Uniforms, } \\
\circ & \text { Continuing training for the staff, } \\
\circ & \text { Central Administration Costs (Supervision Costs) } \\
\circ & \text { Control Costs }\end{array}$ \\
\hline
\end{tabular}

Table 2: Setup and Operating Cost Items of a Rehabilitation Center for 20 Patients

A center with an inpatient capacity for 20 must recruit following staff in minimum: specialized physician (1), specialized clinical psychologist (1), psychologist (2), social worker (2), occupational therapist (3), secretary (2), security staff (6), and nurse. The table below shows the annual staffing cost for a center with 20-patient capacity; the salaries were calculated based on those of civil servants with the same posts.

\begin{tabular}{|l|r|r|r|r|}
\hline \multicolumn{1}{|c|}{ TITLE } & $\begin{array}{c}\text { Number } \\
\text { of Staff }\end{array}$ & $\begin{array}{c}\text { Net Minimum } \\
\text { Wage (Monthly, } \\
\text { per person) }\end{array}$ & $\begin{array}{c}\text { Average Gross } \\
\text { Wage (Monthly, } \\
\text { per person) }\end{array}$ & $\begin{array}{c}\text { Annual Gross } \\
\text { Wage (All } \\
\text { posts) }\end{array}$ \\
\hline Specialized Physician & 1 & $6,882.45$ & $7,974.18$ & $95,690.16$ \\
\hline Specialized Clinical Psychologist & 1 & $4,749.85$ & $5,628.61$ & $67,543.32$ \\
\hline Psychologist & 1 & $4,744.3$ & $5,622.02$ & $67,464.24$ \\
\hline Nurse & 1 & $4,668.16$ & $5,511.25$ & $66,135.00$ \\
\hline Social Worker & 2 & $4,744.30$ & $5,622.02$ & $134,928.48$ \\
\hline Occupational Therapist & 3 & $3,963.52$ & $4,671.1$ & $168,159.60$ \\
\hline Secretary & 2 & $4,048.93$ & $4,771.97$ & $114,527.28$ \\
\hline Security Staff & 6 & $3,106.85$ & $3,893.44$ & $280,327.68$ \\
\hline \multicolumn{3}{|r|}{} & \multicolumn{3}{|c|}{ TOTAL } & $\mathbf{9 9 4 , 7 7 5 . 7 6}$ \\
\hline
\end{tabular}

Table 3: Annual Minimum Staffing Cost of a Rehabilitation Centre with 20 Employees (TRY) Source: Memurlarnet / https://www.memurlar.net/maasrobot/

Other than the staffing cost, the table below shows approximate estimates of set-up and operating costs calculated by comparison to current market rates.

\begin{tabular}{|l|r|}
\hline INVESTMENT COST ITEMS & AMOUNT (TRY) \\
\hline Land Cost & $1,000,000$ \\
\hline Construction Cost & $2,625,000$ \\
\hline $\begin{array}{l}\text { Equipment and Furnishing (IT Infrastructure, Furniture, Whiteware, Fittings, etc. } \\
\text { included) }\end{array}$ & 178,692 \\
\hline Staff Training & 82,300 \\
\hline Vehicle for Transportation & 130,000 \\
\hline \multicolumn{2}{|c|}{ TOTAL } \\
\hline
\end{tabular}

Table 4: Investment Cost Items of a Rehabilitation Center

\begin{tabular}{|l|r|}
\hline OPERATING COST ITEMS (ANNUAL) & AMOUNT (TRY) \\
\hline Salaries (severance pay included) & $1,126,775.8$ \\
\hline Operating expenses: & 51,000 \\
\hline Electricity, Water, Gas, Telephone, Internet services & 25,000 \\
\hline Transportation & 405,150 \\
\hline Kitchen/Food & 24,500 \\
\hline Consumables (Cleaning materials, stationery, uniforms, etc.) & 30,000 \\
\hline Maintenance \& Repair and Insurance & 10,000 \\
\hline Central Administration Costs (Central Control, Supervision and Management Costs) & 10,000 \\
\hline Unforeseen Expenses & $\mathbf{1 , 6 8 2 , 4 2 5 . 7 6}$ \\
\hline
\end{tabular}

Table 5: Operating Cost Items of a Rehabilitation Center 
For a rehabilitation center with 20-patient capacity, cost induced by one consulee/addict is 230,47 TL per day on the assumption that the center operates in full capacity year-round. This amount approximates to 247,72 , which is the procedure score used for (F-10-19) mental and behavioral disorders caused by psychoactive substance use (excluding F-15-17 code groups) under Group 5-Psychiatric patients' daily treatment as stated in the Health Application Communiqué (SUT), Appendix-2/C, Diagnostic Procedure Score List. This proximity reinforces the rationality and significance of the modeling and estimation methods employed in this study.

Payback period must also be addressed in the modeling by reflecting the set-up costs of the centers to their service life. Again on the assumption that a center with a capacity of 20-patient operates in full capacity over years, the return on a center's investment cost is calculated as stated below if we are to compute centers' investment payback period by using the amount to be saved for each patient due to the difference between break-even level of 230.47 TL needed to cover the operating costs and the basis point of 247.72 designated in the SUT;

$247.72-230.47=17.25 \times(20 \times 365=7300)=125,925$

Investment Cost Total / Annual SUT income net of operating costs= Investment payback period 4,015,992 / 125,925 = 31.89 YEARS.

Meanwhile, 247,72 procedure score is equivalent of same amount of Turkish Lira at the time when it was first introduced in 2018. Since then regular increase is not applied to this amount although procedural points of many other treatment expenditures are subject to incremental change with respect to increase in economic indicators such as inflation.

Even if investment into rehabilitation centers, within this perspective, may not be seen reasonable with respect to investment efficiency, every penny spent on rehabilitation achieve 21 -fold return over a 10 -year period, as stated previously above. In that regard, it can be concluded that governing power should support this field or augment particularly services focused on this field.

Besides, if we consider that each year number of substance addiction inpatient detoxification treatment to be served to 15.000 people in a year and each patient is subject to AMATEMS' 21 days of detoxification program then it counts $15,000 \mathrm{X} 21=315,000$ days of inpatient treatment in for a year. If we multiply this number by the daily SUT basis point of 247,72 we reach 78,031,800 TRY of yearly inpatient detoxification cost, as an assumption.

However, psychological and social rehabilitation of drug addiction needs generally more time than 21 days, three months at least according to the observations results. Therefore, a risky group of detoxification inpatients should be sent to the rehabilitation centers. If we assume that half of them transferred to the rehabilitation centers, then the number of rehabilitation inpatients would be 7,500 or 8,000 in round with respect to the 15,000 of inpatient detoxification inpatient as it is indicated above. Regarding 3 months of rehabilitation period for each patient then it makes $8,000 \mathrm{X} 90$ days $=720,000$ rehabilitation service days each year and the yearly costs may be calculated as $720,000 X 230,47=165,938,400$ TRY.

Aligned with present AMATEMs and CEMATEMs, rehabilitation services may start by establishing 40 centers across Turkey. But 40 centers for 20 people each would have 292,000 days of yearly impatience capacity, but the capacity required for 8,000 patients for three months of rehabilitation is 720,000 as indicated above. Therefore, number of rehabilitation centers must be increased gradually.

However, with respect to the ratio of drug treatment has a social return of 21 pounds over a 10 -year period, then $165,938,400$ TRY cost of 8,000 patient rehabilitation in a year will provide saving of 3,484,706,400 TRY.

\section{Conclusion and Suggestions}

Healthcare services differ from other sectors for their societal features and appeal to the whole society. And they seek to enhance and improve health conditions across society. As those services are considered full or partial public goods, state interventions are intensive in the field. Although the state intervenes in many service sectors the most interventions take place in the healthcare services sector and this is how the healthcare services market is shaped.

In this framework, addiction is not only a physiological disease but also a brain disease; and it is directly related to sociological and environmental impacts. On the other hand, it is an urgent issue for Turkey to develop a system that is focused on medical and psychotherapeutic treatment within a functional harmony. With the development of the system, an integrated mechanism should be established to provide psychological and social support services. Because the individuals who return to the same social environment without getting any support after medical treatment go back to the addiction cycle inevitably. The current situation lower treatment success rates whereas the addicts resuming the medical treatment over and over put great pressure on AMATEM and CEMATEMS. Treatment success rates are likely to go up substantially with the foundation of rehabilitation centers.

One of the reasons for state intervention in the healthcare sector is that market failures occur detracting the sector away from Pareto efficiency when the sector does not produce health-related goods and services effectively. The state remains the most influential actor in the healthcare sector for a justification that forms the foundation of the market failure theory, one of the most significant financial theories. 
In consideration of the findings in this study and the societal and economic dimension of healthcare services, there is obviously an urgent need to disseminate rehabilitation services for drug addicts by or under the control of public authorities.

\section{References}

- Alexandre, Pierre \& Beulaygue, Isabelle \& French, Michael \& McCollister, Kathryn \& Popovici, Ioana \& Sayed, Bisma, 2012. "The Economic Cost of Substance Abuse Treatment in the State of Florida". Evaluation Review. 36. 167-85. 10.1177/0193841X12450164.

- AMATEM - ÇEMATEM, (n.d.). Retrieved from https://alo191uyusturucu.saglik.gov.tr/TR,15589/amatem--cematem.html

- Cartwright, W S, 1998. "Cost-benefit and Cost-effectiveness Analysis of Drug Abuse Treatment Services". Evaluation Review, 22. Retrieved from http://www.biomedsearch.com/nih/Cost-benefit-cost-effectivenessanalysis/10186896.html

- Degenhardt, Louisa \& Hall, Wayne. 2012. "Extent of Illicit Drug use and Dependence, and Their Contribution to the Global Burden of Disease." Lancet. 379. 55-70. 10.1016/S0140-6736(11)61138-0.

- Drug Related News. (n.d.) Retrieved from https://alo191uyusturucu.saglik.gov.tr/TR,25452/haberler.html

- EMCDDA, 2017. "Drug Treatment Expenditure: A Methodological Overview, EMCDDA Insights", Publications Office of the European Union, Luxembourg. Retrieved from

- EMCDDA, 2019. “Turkey Drug Report.” Retrieved from http://www.emcdda.europa.eu/countries/drugreports/2019/turkey/drug-induced-deaths_en

- EMCDDA. 2019. "European Drug Report.” Retrieved from http://www.emcdda.europa.eu/edr2019_en

- French M.T., 2002. "Economic Evaluation of Alcohol Treatment Services." Recent Developments in Alcoholism (Services Research in the Era of Managed Care), vol 15. Springer, Boston, MA

- French MT, Salomé HJ, Krupski A, McKay JR, Donovan DM, McLellan AT, Durell J., 2000. "Benefit-Cost Analysis of Residential and Outpatient Addiction Treatment in the State of Washington." Evaluation Review. 2000;24(6):609-34. PubMed Retrieved from https://www.ncbi.nlm.nih.gov/pubmed/11151519

- French, M. T., Salomé, H. J., Sindelar, J. L., \& McLellan, A. T., 2002. "Benefit-cost Analysis of Addiction Treatment: Methodological Guidelines and Empirical Application Using the DATCAP and ASI." Health Services Research, 37(2), 433-455. doi:10.1111/1475-6773.031 Retrieved from https://www.ncbi.nlm.nih.gov/pmc/articles/PMC1430361/

- French, M., 1995. "Economic Evaluation of Drug Abuse Treatment Programs: Methodology and Findings." American Journal of Drug and Alcohol Abuse, 21(1), 111-135. https://doi.org/10.3109/00952999509095233

- Public Health England, 2012. "Alcohol and Drug Prevention, Treatment and Recovery: Why Invest?" Retrieved from https://www.gov.uk/government/publications/alcohol-and-drug-prevention-treatment-andrecovery-why-invest/alcohol-and-drug-prevention-treatment-and-recovery-why-invest

- Rehm J, Gmel GE Sr, Gmel G, et al., 2017. "The Relationship Between Different Dimensions of Alcohol Use and the Burden of Disease-an Update. "PubMed - NCBI. Retrieved from https://www.ncbi.nlm.nih.gov/pubmed/28220587

- Salomé H.J., French M.T., 2002 Using Cost and Financing Instruments for Economic Evaluation of Substance Abuse Treatment Services. In: Alcoholism. Recent Developments in Alcoholism (Services Research in the Era of Managed Care), vol 15. Springer, Boston, MA

- T.C. Resmi Gazete, 2019. "Bağimlilik Danişma, Arindirma Ve Rehabilitasyon Merkezleri Hakkinda Yönetmelik." Retrieved from https://www.resmigazete.gov.tr/eskiler/2019/03/20190310-2.htm

- TUBIM - Turkish National Monitoring Centre for Drugs and Drugs Addiction, 2018. "Türkiye'de Genel Nüfusta Tütün, Alkol ve Madde Kullanımına Yönelik Tutum ve Davranış Araştırması Raporu.” Retrieved from http://www.narkotik.pol.tr/turkiyede-genel-nufusta-tutun-alkol-ve-madde-kullanimina-yonelik-tutumve-davranis-arastirmasi-raporu-yayimlanmistir

- TUBIM - Turkish National Monitoring Centre for Drugs and Drugs Addiction, 2014. Retrieved from http://www.narkotik.pol.tr/kurumlar/narkotik.pol.tr/Arsiv/TUBIM/Documents/TURKIYE\%20UYUSTURU CU\%20RAPORU\%202014.pdf

- $\quad$ Ulu, Ö., 2018. “Türkiye'de ve Dünyada Uyuş̧urucu İle Mücadele.” 1st ed. TİAV Türk İdari Araştırmalar Vakfi İktisadi İşletmesi. p. 330

- UNODC, 2019. “World Drug Report.” Retrieved from https://wdr.unodc.org/wdr2019/

- WHO, 2018. "Noncommunicable Diseases." Retrieved from https://www.who.int/news-room/factsheets/detail/noncommunicable-diseas 